\title{
CONGLOMERATE MERGERS: EXTENDED INTERDEPENDENCE AND EFFECTS ON INTERINDUSTRY COMPETITION AS GROUNDS FOR CONDEMNATION *
} Phillip Areeda $\uparrow$ and Donald Turner $\ddagger$

\section{INTRODUCTION}

Some mergers will merely substitute a new owner for the acquired firm, without thereby affecting the performance or conduct of either of the two merging firms, or changing the market structure. Other mergers will bring about each of these effects, even though the merging parties neither compete directly nor deal vertically with each other. A firm's improper or anticompetitive conduct, or its rivals' fear of such conduct, can diminish the willingness and ability of rivals to compete and of outsiders to enter the affected market. Thus, such conduct can create or fortify barriers to new entry or affect rivals' competitiveness and thereby become a factor in appraising market structure and its effect upon competition. However, this Article does not address the ways in which a conglomerate merger might facilitate such conduct as reciprocity or predatory pricing. Nor do we consider the cost savings or other benefits that might accrue to the merged firm as a result of the merger, thereby "entrenching" the merged firm in its new market position. Here we consider only the structural and performance implications that may arise from a merger of firms not in a close horizontal or vertical relationship.

The most frequently discussed structural change is the entry via merger of a firm into a market that it might otherwise have entered "at the grass roots." But this type of merger, which eliminates a potential competitor, will not be discussed here. Instead, this Article will examine two other ways in which conglomerate mergers may alter market relationships. First, they may bring multi-product firms into contact with each other in more than one market; this wider exposure to competitive retaliation may create an interdependence that discourages aggressive price cuts or other

- Copyright (C) 1978-79 by Phillip Areeda and Donald Turner. This Article is adapted from 4 P. AREeDA \& D. TURNER, ANTITRUST LAw (forthcoming 1979). This Article has benefited from criticisms of an earlier version kindly offered by Professors Richard Caves and Joseph Brodley.

$\uparrow$ Professor of Law, Harvard University.

tf Professor of Law, Harvard University. 
competitive responses that might otherwise be made. Second, mergers across markets that are largely separate but whose products are to some extent substitutable may have adverse price effects similar to those caused by conventional horizontal mergers.

\section{EXTENDED INTERDEPENDENCE}

\section{A. The Possibility}

The primary concern with oligopoly is that rivals will mutually forebear from vigorous price competition. Each of the large firms dominating an oligopolistic market knows that its efforts at competitive pricing will prove futile, in that rival firms will almost certainly match any open price reduction before it has secured for its proponent any large increase in market share. Ordinarily, no large firm will initiate a price cut the principal effect of which is to lower aggregate industry profits. For these reasons oligopolists tend to engage in collective monopoly pricing.

Nevertheless, certain circumstances can induce one or more firms in an oligopolistic market to behave aggressively, thus producing substantial rivalry and even, at times, leading to "workably competitive" results. For example, oligopolists with different costs, market shares, current capacity utilizations, or demand assessments may hold substantially different views about the efficacy of a price cut. Thus, a particular oligopolist may regard such cuts as advantageous, either as part of a temporary promotional campaign that others hesitate to follow, or as a relatively permanent reflection of that firm's lower costs. That is, an aggressive firm may be able profitably to expand output even if every other firm in the market follows its price reduction.

Thus, a particular oligopolist may occasionally make competitive price moves, hoping thereby to increase its profits in that particular market despite probable countermoves by rivals in that market. However, when the same oligopolist and his rivals confront each other in several different markets, the effect may be further to deter competition. Firm $A$, for example, may hesitate to reduce price in market \#1 (MI) when it fears that rival $B$ may retaliate not only in that market but in market \#2 (M2) as well. Before making a rivalrous move in M1, Firm $A$ must calculate and balance the long-term effects on its profits in both $\mathrm{M} 1$ and M2. The cumulative effect of multiple retaliations in different markets may be sufficiently threatening to deter Firm $A$, and each of its rivals, from making any price cuts at all. In short, firms with similar interests in different markets may recognize their interdependence across a 
broader front. ${ }^{1}$ They will refrain from upsetting non-competitive oligopolistic pricing in one market when they also inhabit a second market in which they compete. ${ }^{2}$ This effect, which we call "extended interdependence," may exist no matter how the firms came to confront each other in more than one market. Of course, one obvious cause of a multi-market confrontation is the conglomerate merger.

Thus far the discussion has focused only on possibilities. To say that conglomerate mergers may produce this anticompetitive effect is not to say that they will do so. There are several minimum conditions that must be met before this anticompetitive effect can occur; even when these conditions are met, the resulting effect would probably be minimal.

\section{B. Necessary Conditions: General Incidence vs. Proof in Particular Cases}

Unless each of the three conditions described below is satisfied, there can be no extension of interdependence or, if there is such an extension, no significant anticompetitive effect from it. Whether these conditions can actually be proved in particular cases ${ }^{3}$ need not be considered here, in view of our conclusion that conglomerate mergers seldom produce the kind of extended interdependence that is the focus of this inquiry.

1. The merged firm and at least one rival must confront each other in two markets, each of which is somewhat oligopolistic in performance but not rigidly so. There are several reasons for this condition. First, unless the original market inhabited by the acquired firm is oligopolistic, with significant departures from competitive price and output performance, there can be no interdependence to be extended. ${ }^{4}$ Second, if the acquiring firm does not

1 See Newman, Strategic Groups and the Structure-Performance Relationship, 60 Per. Econ. \& Statistics, 417-27 (1978).

2 The same possibility arises when one of two competing firms also buys a product sold by the other. That situation will not be analyzed in detail here because the relevant factors are so similar to those that bear upon reciprocity.

3 As a practical matter, it might be necessary to ignore some of these conditions as unprovable in actual cases. However, if an unprovable necessary condition is not likely to be fulfilled-that is, if it is both unprovable and improbable-there would be no reason to prohibit the merger. Thus, even as to matters that are not readily provable, we must understand all the prerequisites for significant anticompetitive effects in order to gauge whether there is cause for concern and a need for preventive efforts.

4 We shall use the convenient convention of looking for anticompetitive results in the "first" market, which we attribute to the acquired firm. Of course, the harm might be felt in the market of the acquiring firm. Nevertheless, the text will be 
inhabit some second, oligopolistic market, there can be no discretionary behavior in the second market to affect behavior in the first. Moreover, the second market must contain at least one other firm that competes with the acquired firm in the first market; otherwise, events in the second market cannot influence behavior in the first. $^{5}$ Finally, at least one of the markets must be less than rigidly oligopolistic; if both were already rigid, they could not be made significantly worse by the merger. Although extended interdependence might impede any future relaxation of such oligopolistic rigidity, its effect is so speculative to begin with that we would discount it altogether in those situations in which the markets involved are already rigidly noncompetitive.

In short, the problem is to identify the "moderate" oligopoly that extended interdependence might significantly affect. This task is complicated by the difficulty of proving that there is enough competition to be worth saving from extended interdependence. The greater the competition to be preserved, the less likely it is that the market is the kind of relatively uncompetitive oligopoly in which interdependence can exist. Certainly there may be noncompetitive oligopolies that still retain some rivalrous vitality, which might be impaired by extended interdependence. To identify such markets, however, requires the use of the complex, detailed, and refined inquiries into structure and performance that are appropriate in an occasional "shared monopoly" case ${ }^{6}$ but that are wholly unmanageable in the. application of an anti-merger statute. Any effort to solve the problem by formulating rules based on market-concentration ratios-for example, four-firm ratios of fifty-five percent or more, or eight-firm ratios of seventy-five percent or more-cannot succeed because such ratios are a hopelessly crude means of isolating the markets in which extended interdependence might have a significant effect, even assuming it would be a common phenomenon.

2. The merged firm and at least one other two-market firm must both be significant in both markets, and both markets must be relatively important to both firms. Both markets must be important to both firms because events (or the fear of events) occur-

made shorter and clearer by speaking only of possible harmful effects in the first market, which is that of the acquired firm.

5 One might worry about the future possibility that a single-market rival to the acquired firm would later enter the second market, either by merger or by internal expansion. To object to a merger on this ground, however, would approach universal condemnation of conglomerate mergers.

6 See 3 P. AREeda \& D. Turner, ANTitrust LAw 359-90 (1978). 
ring in a market that is relatively unimportant to a firm are not likely to affect its profit-maximizing moves in a different, more important market. Moreover, unless the relevant two-market firms are relatively significant competitive forces in each of the two markets, their moves and forebearances will not determine the economic performance of those markets. It is unlikely that a firm would refrain from a profitable, rivalrous move in the first market out of fear of retaliation in a second market in which it is not a significant force. The market in which a firm is relatively insignificant may also be relatively unimportant to its overall fortunes. More important, a significant firm in the second market would ordinarily base its decisions there on the interests and prospective reactions of its significant rivals in that market. When calculating its interests in a market that is important to it, a significant firm cannot afford to focus upon the reactions of a conglomerate rival in some other market in which that rival is insignificant. ${ }^{7}$

The concept of "significance" as used here is more readily invoked in principle than proved in fact. But it is a reasonable presumption that a firm with fifteen or twenty percent of a concentrated market is "significant." Furthermore, a somewhat smaller firm that is growing rapidly or that has been a "disruptive" market factor may also be "significant" as that term is used here.

3. To be deterred from a price cut in one market a firm must be subject to sanctions in the second market. The situation in a second market cannot deter two-market Firm $A$ from a price cut or other competitive move in the first market unless another twomarket company, Firm $B$, can subject the former to unfavorable consequences in that second market. This could occur if Firm $B$ is unable to retaliate in $M I$ or simply finds retaliation cheaper in M2. Firm $A$ could suffer two sorts of unpleasant consequences in the second market: its rival, Firm $B$, might be induced to exploit a previously unexploited advantage, or might engage in predatory or "spoiling" activity. Each of these possibilities will now be examined.

a. Previously unexploited disadvantage in the second market. It is possible that Firm $A$ knows it has a previously unexploited disadvantage in the second market that Firm $B$ will exploit once $A$

7 It should be noted that the parallel significance discussed here can come about through chance or through the parallel responses of different firms to common economic forces. If, for example, two markets are related such that efficiencies can be achieved by operating in both at a certain scale, one could expect to find several diversified firms operating in both markets and at least at that scale. 
has made an aggressive competitive move in the first market. But that situation can occur only if there is some reason for the stronger Firm $B$ previously to have sacrificed maximum profits in that market in order to accommodate its weaker rival. There are two possible reasons why Firm $B$ might have shown restraint. First, a combination of ignorance and inertia might have kept it from perceiving and exploiting its advantage in the second market over the weaker firm, until the latter challenged its overall profits by aggressive competition in the first market. The second possibility is that Firm $B$ might have had a reciprocal disadvantage in the first or some other market in which it feared retaliation. These circumstances, though possible, seem far too unlikely to warrant a general condemnation of conglomerate mergers among moderately oligopolistic markets.

b. Spoiling the Second Market. Firm $A$ may fear Firm $B$ 's reaction in the second market, not because $B$ is stronger there but because it is weaker. If $B$ is smaller than $A$ in the second market, $B$ 's retaliatory price reduction in that market would reduce $A$ 's profits more than $B$ 's. That is, $B$ might be able to "spoil" $A$ 's situation in the second market at relatively little cost to itself, and thereby both punish and deter $A$ from competition in the first market. There may indeed be circumstances in which this scenario could occur, but the preconditions for it would be quite severe. These can be illustrated by an example.

After $A$ has made aggressive moves in the first market, suppose $B$ retaliates by reducing its $M 2$ price below the previously profitable and satisfactory level. It is not important to specify either the level of the price cut or its relationship to $B$ 's costs; the argument requires only that $A$ earn substantially less than it did before the price cut, and that its loss of profits be much more severe than that of the spoiler $B$. But the only way in which $A$, as well as other firms in the second market, can be hurt substantially (and thus forced to lower prices) is if $B$ can both lower its prices and expand its sales substantially; otherwise, customers cannot shift enough of their patronage to $B$ to force the other suppliers, including $A$, to cut their prices. It is implausible, however, that $B$ would build new capacity solely for the purpose of spoiling; the expanded capacity would increase $B$ 's volume of sales, on which it would earn, under the argument's assumptions, less than it otherwise could. Although such expansion may be a profitable way for $B$ to build sales and thus obtain a higher market share and higher profits after prices return to a satisfactory oligopoly level, this activity may not be termed 
"spoiling"; rather, it represents the seizure of a profitable opportunity undertaken independently of any effort to retaliate for events in a different market. If the argument is that Firm $B$ only chooses to seize this profitable opportunity as a reaction to $A$ 's move in the other market, the issue becomes that of the unexploited opportunity, which has already been discussed. ${ }^{8}$

Other factors also restrain firms from retaliation through spoiling. For example, Firm $B$ may hesitate to punish $A$ if it knows that its actions may thereby destroy an oligopolistic consensus from which it, as well as the other oligopolists of the market, has profited. This is not to say that retaliation would not occur, or that Firm $A$ would always be unconcerned about reactions in the second market. Even a small expansion of $B$ 's sales in the second market could, in some cases, harm $A$ or trigger a reaction by other firms which, in the aggregate, have sufficient capacity to force $A$ to lower price and thus to suffer in the second market. Or perhaps a retaliatory motive might induce Firm $B$ to risk a price reduction that might prove independently profitable or, if not, might be worth doing in order to harm $A$. That is, $B$ might otherwise have refrained from making any price cut, due to the common concern among oligopolists that such moves only reduce each rival's profits without affecting the distribution of shares. But $B$ might be willing to take that risk if a retaliatory motive made it relatively indifferent to a profit decline in the second market. That is, adding a retaliatory impulse to the possibility that others might not respond could induce $B$ to reduce its price, which might lead to an increased share in that market and perhaps to even greater profits if prices ultimately stabilize at an attractive oligopoly level. ${ }^{9}$

8 Of course, Firm $B$ may already have substantial idle capacity in that market or available to it; without having to build any new capacity, $B$ can use its idle capacity to hurt A. Again, however, if the idle capacity were large enough to permit substantial expansion by $B$, it would be under heavy pressure to shade prices anyway, and might even find expansion profitable; this, too, would be simply a case of previously unexploited opportunity.

9 Our discussion of extended interdependence and mutual forbearance has focused on the self-restraint exercised by Firm $A$ in market $M I$ because of its fear that $B$ will retaliate in $M 2$. In that framework, we have suggested that unless $M 2$ is quite important to $A$, that firm would not refrain from profit maximization in $M I$; and $A$ must have an unexploited disadvantage or otherwise be subject to unpleasant consequences in $M 2$ if his behavior in $M I$ is to be influenced.

There are no substantial changes in the analysis when one focuses on the case in which Firms $A$ and $B$ have opposite roles in the two markets-for example, where $A$ dominates $M 1$ while $B$ dominates $M 2$. Would $A$ then cede price leadership in $M 2$ to $B$ "in return for" $B$ 's similar behavior in MIP This turns out to be a variation of the situations discussed in the text: that is, can Firm $A$ "spoil" the oligopolistic consensus in $M 2$, which is of great concern to $\operatorname{Firm} B$, if $B$ becomes too rivalrous in $M I$ ? 
These are possibilities, but they cannot be said to be probable in all or most cases in which several firms confront each other in several different markets. The more likely alternatives are that spoiling will be ineffective or that the potential spoiler will regard its gains as either too speculative or too ephemeral to justify upsetting the oligopolistic consensus. If a firm really believes that its aggressive moves will permit it to capture and hold a larger share of the market, then its actions are not retaliatory in character. For these reasons, it is unlikely that the attenuated threat posed by a potential spoiler in $M 2$ would be sufficient to deter Firm $A$ from pursuing its pricing policies in $M 1$.

One further point should be noted. Whatever may happen after the fact, a firm would rarely if ever plan a conglomerate acquisition merely to foster extended interdependence. A firm with a strong position in one market would have no incentive to acquire a vulnerable firm in a second market if the principal effect of that acquisition were to reduce its perceived ability to make profitmaximizing moves in the first market. Nor is there any reason for a firm vulnerable in one market to acquire a strong firm in a second market if the vulnerability reduced its felt ability to exploit the strong firm's position. Although a firm strong in one market might believe it advantageous to acquire a minor firm in a second market to use as a "spoiler" to discipline a firm that was important in that market and also a significant rival in the acquirer's market, we doubt that this would often occur. Whatever anticompetitive advantages the acquiring firm gains by having available this distant threat must be balanced against the cost of acquiring and maintaining a minor firm solely for the purpose of possible use as a "spoiler." On balance, that benefit seems highly speculative.

\section{Effect on Innovations}

Up to this point, this Article has focused solely upon the possible effect of extended interdependence in deterring price competition; other modes of competition have not been considered. It has been suggested that a substantial deterrent to price competition may occur, if at all, only if the merger meets certain quite restrictive conditions. Yet even when those conditions are met, there is no reason to believe that the merger will produce any significant adverse effect on competition in innovations.

Although oligopoly may deter price competition, it seldom, if ever, diminishes technological or other innovational competition. Unlike a price cut, an innovation, particularly if patentable or con- 
cealable, cannot be quickly matched. Thus an innovating firm can often obtain, for itself alone, substantial rewards from its innovations. Innovative effort is also stimulated by the fear of substantial loss from the innovations of rivals. In short, insofar as innovational competition is concerned, there is much less "interdependence" among the firms within an oligopolistic market. Thus, there is no reason to fear the effects of extended interdependence upon innovational rivalry, because in this case there is nothing to be extended.

It is quite implausible that parallel conglomerate presence in several markets would have any additional deterrent effect upon innovation. Clearly this is true with respect to conglomerates selling the same product in separate geographic markets. Product improvements or cost reductions resulting from innovation give the innovating firm an advantage in all its markets; thus, it need not fear retaliation in its weaker areas. Even those conglomerates engaged in diverse product markets are not likely to diminish their innovational efforts and thus risk market displacement by innovating rivals, because they fear that discovery and exploitation of a successful innovation in one product market might provoke retaliation in another.

\section{Intermarket and Intramarket Interdependence Compared}

Extended interdependence cannot be an important constraint on behavior within one of two markets unless the minimum conditions described above are met. However, even if the facts of a particular merger satisfy all three conditions, it does not necessarily follow that that merger will produce any unacceptable, anticompetitive effects. Two key points should be stressed. First, the anticompetitive effects of oligopolistic interdependence within a single market are uncertain: both oligopoly theory and the empirical evidence offered to support it remain the subjects of lively dispute. ${ }^{10}$ Second, the effects of interdependence will be even less noticeable, and therefore less verifiable, when measured across two markets rather than in one. Indeed, oligopoly theory and the empirical evidence substantiating it are the Rock of Gibraltar as compared to the speculative theory of interdependence across market lines. The empirical evidence advanced so far to substantiate any adverse effects of extended interdependence has been characterized as ranging from sketchy ${ }^{11}$ to nonexistent. ${ }^{12}$

10 See generally 2 P. AREeda \& D. TuRnER, ANTitrust Law 272-79 (1978).

11 See F. Scherer, Industrial Market Structure and Economi PerformANCE 279-80 (1970).

12 See P. Steiner, Mergers 310 (1975). 


\section{E. How Significant: Conclusions, Presumptions, and Burdens of Proof}

The preceding discussion does not deny (1) that mutual forbearance or extended interdependence might occur and might reduce competition that would otherwise occur; (2) that the likelihood of such results occurring may increase with the number of significant multi-market firms, and; (3) that conglomerate mergers thereby increase the possibility of anticompetitive results in the economy. But these propositions represent abstract "possibilities," which occur at most infrequently, and with dubious effect. Moreover, once in the realm of speculation, one must also admit the possibility that an oligopolist's rivalrous step in one market might trigger a series of highly rivalrous reactions in each of the other markets in which he and his rivals intersect; the net result may be to increase competition in many markets. Competition might also increase if an oligopolist's ability to retaliate in one market increases his willingness to make a competitive move in a different market. In short, one who wishes to oppose conglomerate mergers on the ground that they produce extended interdependence must do more than state that anticompetitive results are possible. To be convincing, he must show that such results are likely to occur in a particular conglomerate merger, in many such mergers, or in the preponderance of conglomerate mergers.

We can state with reasonable confidence these three conclusions. First, because the incidence and importance of extended interdependence are so doubtful, the mere assertion that mutual forbearance is a possible consequence of conglomerate mergers does not provide sufficient justification for condemning these mergers. Second, in order successfully to raise the objection of extended interdependence, a plaintiff seeking to block a merger must first establish that the minimum conditions described above have been met. Third, the difficulties of proof are so severe, and administrable presumptions so lacking in foundation, that it would probably be wiser for courts and litigants to ignore the issue of extended interdependence entirely.

\section{Mergers Affecting "Interindustry" CompettTion A. The Problem Defined}

We have just analyzed the likelihood that a series of conglomerate mergers across market lines might discourage competition in 
one or more markets by increasing the opportunities for retaliation. For this possibility to exist, it is not necessary that the several products involved compete with each other; that is, retaliatory moves might be made in product or geographic markets wholly distinct from the one in which a price cut or other competitive move was initiated.

We will now examine whether additional anticompetitive effects occur whenever a firm participates in two or more product or geographic markets that are not wholly separate-that is, when there is some competition between those markets but not enough to warrant the conclusion that they are parts of the same market for purposes of section 2 of the Sherman Act, or for horizontal merger purposes. Because conglomerate acquisitions in partially competing markets reduce the aggregate number of competing firms, it is possible to argue that parallel cross-ownership by many firms causes the same kind of adverse effects that usually accompany horizontal mergers. In brief, there are two possible reasons for this anticompetitive effect. First, when a firm with a large share of each of two partially competing markets-for example, products $A$ and $B-$ reduces the price on one of them $(A)$, the increased profits it makes in that market are likely to be partially offset by the loss in sales of product $B$, which occurs as some of its customers switch from $B$ to $A$. The firm is thus less likely to reduce price than if it were in one market only.

There is a second, related possibility. Assume, for example, that there are only five $A$ firms and five $B$ firms. If each of the $A$ firms merges with one of the $B$ firms, the reduction in number (from a total of ten firms to only five) may facilitate cooperative, non-competitive pricing; because there are fewer firms, their interdependence will be clearer, and tacit price coordination easier. The result may be increases in the prices of $A$, of $B$, or of both.

However, as was the case with extended interdependence, the likelihood and magnitude of these adverse effects (1) are considerably less than in the case of conventional horizontal mergers; (2) depend upon several highly restrictive conditions; (3) probably do not extend to competition in innovations; and (4) are sufficiently remote that they should probably be disregarded except in extreme cases. The likelihood and magnitude of any possible anticompetitive effect can increase under certain circumstances. These include cases in which the products involved are "close" substitutes; the number of significant sellers of these products, or of equally close substitutes, is very small; or the merging firms are "leading" firms in their respec- 
tive markets. All of these circumstances, in conjunction, might constitute the "extreme" case that warrants judicial intervention.

Each of these points will be examined in detail below. For the sake of simplicity, we will focus only upon the case of two partially competing products, rather than that of partially overlapping geographic markets; the analysis in both instances, however, is the same. Moreover, as will later be shown, the presence of adverse effects becomes less likely as the number of overlapping markets increases.

\section{B. Interindustry and Horizontal Mergers Compared; Market Definition}

In essence, "interindustry competition" reflects the fact that buyers make a heterogeneous evaluation of products with differing characteristics: some buyers do not consider the products as substitutes at all; others consider them substitutes, but at differing relative prices. Whether the products should be included in the same market partially depends on whether the number of buyers who consider them to be highly substitutable is sufficient to keep their price movements closely related. Poorly correlated price movements indicate that the producers of Product $A$ can exert only a slight influence on the price of $B$; they do not affect $B$ 's prices as much as do firms actually producing $B$, and they could not prevent the non-competitive pricing of $B$ if $B$ 's market became a wellfunctioning oligopoly. Consequently, the market for testing a merger of two $B$ producers is correctly defined to include the output of that product only.

To be sure, the effects of a merger of an $A$ producer with a $B$ producer will approach those of a standard horizontal merger as the two products approach perfect substitution. Nevertheless, as long as the two products would normally be assigned to separate markets, two conclusions can be drawn. First, the competitive loss from a merger of two $A$ (or $B$ ) producers presumptively exceeds that from a comparably sized merger of an $A$ and a $B$ producer. For example, the anticompetitive effect of a merger between two of four equivalent firms operating in one market, or between two of eight such firms, is necessarily greater than that of a merger between two firms from two related markets, each of which has four equivalent firms. Second, in evaluating a merger between an $A$ and a $B$ producer, it would be delusive to abandon correct market definition principles, define the market as $A$ plus $B$, and assess the merger by tallying the merging firms' shares of aggregate $A$ and $B$ output. 
Interindustry mergers must be analyzed in terms of the minimum conditions for anticompetitive effects that are both likely and substantial. Three such conditions will be identified and discussed below. Thereafter, we will examine the effect of interindustry mergers on innovation.

1. Both markets must be non-competitive. If one or both of the products of the conglomerate firm are sold in a highly competitive market, cross-market ownership can create no anticompetitive price effects. A competitive market dictates the prices charged by its firms. That those firms also sell one or more other, related products in a different market does not alter the structure of the competitive market, or the behavior of any of the firms operating in it. Because activities in the competitive market are unaffected by events occurring elsewhere, a monopolist or oligopolist in a second market would have no incentive to alter its behavior in that second market in an attempt to influence the competitive market.

Consider the case of a major oil producer's acquisition of a significant coal producer. Ignore any geographical peculiarities or the presence of highly specialized products, and assume that coal production generally occurs in a highly competitive market. Because this merger between one coal and one oil company does not affect the structure of either industry, it does not reduce interproduct rivalry in price or marketing. Because the coal industry is competitively structured, no firm has discretionary power over coal prices. It does not matter if the merged firm is a monopolist or an oligopolist in the production of oil. The market will still determine its coal prices. The firm's control over oil gives it no additional power over the sale of coal. Consequently, its oil decisions must still be made on the same basis as before the merger.

2. The two-market firm must be able to affect price in both markets. Even if both partially related markets are significantly non-competitive, cross-market ownership is not likely to have a substantial, adverse price effect unless the two-product firm has substantial power to affect price in both markets. But even a two-market firm with sufficient power would seldom have the incentive to act differently than would a single-market firm.

A two-market firm not dominant in one of its markets would not raise its price in either market above the profit-maximizing level for that market alone; if it tried to do so, its independent rivals in that market, who are concerned only with their profits there, would refuse to follow the price increase. As a result, the two-market firm's increase could not be sustained. 
If dominant in one of the markets, the two-market firm could sustain a price increase there for the purpose of deflecting sales to the second market. But unless it was dominant in the second market as well, the firm would seldom make such a move, for the primary beneficiaries would be the independent firms in the second market. Consequently, unless a two-market firm dominates both markets, cross-market ownership probably will not cause distortions in either market.

To be sure, a firm need not be dominant in order to affect price. A non-dominant but significant firm can influence the behavior of its rivals. A price reduction by a firm with, for example, a twenty percent market share is likely to be imitated by its rivals. Although the non-dominant firm cannot force others to follow its price increases, it might refrain from leading a price decrease in one market in order to profit in a different one. However, such moves could only be temporary-the non-dominant firm could not effectively influence prices in the first market over a long period of time unless it had a substantial and permanent cost advantage over its rivals there. It would be rare indeed, however, for a firm to refrain from exploiting such an advantage in its first market in order to avoid diverting sales away from a second, related market; such reticence would be almost inconceivable unless the firm were dominant in that second market.

Thus, cross-market ownership would probably have no adverse price effects in either market unless the two-market firm is dominant in at least one, and more likely both, of the markets.

3. Two-product firms collectively dominating both markets must occupy roughly symmetrical positions in both. We next consider whether several two-product firms, acting collectively, can suppress competition in one market in order to enhance profit in the other market. ${ }^{13}$ It is instructive to compare such firms with the situation of a monopolist who controls two related products, $A$ and $B$. The monopolist would not seek to maximize profits on $A$ alone or on $B$ alone, but instead would set that pair of prices that maximized his overall profits. ${ }^{14}$

13 The fact that one cross-market merger has occurred does not imply that other cross-market mergers will occur; nor does legal permission for one merger necessarily imply permission for successive mergers. Nevertheless, we are discussing the case that might seem most threatening to competition: parallel cross-market mergers that reduce substantially the number of independent decisionmakers in the two markets.

14 As compared with the situation in which each of two independent monopolists controls one of two markets, a monopolist controlling both markets will charge higher prices when the two products are substitutes (such as oil and coal) but lower prices when the two products are complements (such as auto frames and auto motors). See, e.g., 3 P. AREEDA \& D. TURNER, supra note 6, at 200-04. 
By contrast, two or more two-product firms operating in the same two markets would not react that way unless each had similar interests in both markets. For example, a firm with a predominant interest in the $B$ market would not want to sacrifice profits there in favor of greater profits in the $A$ market where its interest was substantially smaller. ${ }^{15}$ No rational firm would surrender profit in one market unless its incremental gain in the other market was at least as great. Thus, even if express collusion were permitted, several two-product firms without symmetrical interests in the two markets would have difficulty agreeing on a mutually satisfactory pair of prices, unless they could agree on a pooling and division of profits.

In the absence of express collusion, coordination among firms with different interests is even less likely. Moreover, as the number of product markets increases, so too does the likelihood that the firms will have divergent interests; thus, the difficulties of coordination multiply. In short, after cross-market mergers have been made, interindustry competition may continue more or less as before.

It should be emphasized that the condition described herethat each firm have symmetrical interests in each market-is not categorically "necessary" to produce anticompetitive effects. Even two conglomerates with diverse interests may at times reluctantly forego competition and acquiesce in price stability as the lesser of evils. This is especially true when only a few firms control both markets. Moreover, it is possible that pre-merger, interproduct competition could be sufficient to keep the prices of both products below profit-maximizing levels; thus, after the merger, the merged firms would have convergent interests in raising prices, a move that cross-market ownership could facilitate. As will become evident, neither of these points is compelling. There are several reasons for this conclusion.

First, that firms have been able to accommodate some of their diverse interests in a single market does not necessarily mean that they could accommodate significant diversities between different markets. Nor is it clear that such an accommodation would produce significantly higher prices.

Second, in the unusual event that the firms in each of two markets perceive their interests as sufficiently similar to raise both prices, their desire or ability to do so will not depend upon the presence or absence of cross-market ownership. To the extent that "cross-market ownership" implies that there will be very few de-

$15 \mathrm{~A}$ firm may prefer one product over another because in the former market it has greater sales, greater excess capacity, lower relative costs, or some other competitive advantage. 
cisionmakers, it does tend to facilitate cooperative price setting. Parallel mergers among the five firms in each of two related markets, for example, could increase the likelihood of tacit price coordination affecting both markets. However, as long as there are many decisionmakers, the fact that some produce partially substitutable products in separate but overlapping markets is irrelevant to price determination.

Third, interproduct competition would not often be decisive in keeping prices below profit-maximizing levels unless it were manifested in a fairly high correlation in the products' price changes-in short, unless the two products are so closely competitive that they should be treated as parts of the same market. If that were the case, however, the issue would involve horizontal rather than conglomerate merger. The absence of price correlation indicates that if prices have been kept below profit-maximizing levels, intraindustry, not interindustry competition is responsible; interindustry mergers cannot change that result. Of course, this is a matter of degree. Markets can be separate and yet close enough to limit each other, such that important competition would be lost if the firms in those two markets could effectively but tacitly coordinate prices.

Fourth, joint profit maximization, although otherwise possible, may be impeded by the availability of other close substitutes. Suppose, for example, that cans and bottles are properly placed in separate markets, but that there is enough interindustry competition between them to justify concern (for all of the reasons already discussed above) over a can firm's merger with a bottle firm, and especially with parallel mergers among all of the major can and bottle firms. The resulting threat to competition, if any, would be reduced if another substance, such as plastic or cardboard, were available for use as a substitute for cans and bottles. Consider again the prospective behavior of a monopolist who controls both the can and bottle markets. If plastic were unavailable or unusable as a substitute, the monopolist's control over both cans and bottles could permit it to set a higher price for each than that set by one that controlled only one market and was faced with perfect competition in the other. But if plastic is as good a substitute for cans as are bottles, ${ }^{16}$ then a monopolist who controls the can market would not increase its ability to raise can prices merely by acquiring a monopoly in the bottle market. Just as its can price previously was

16 This assumption does not mean that bottles and plastic are in the same market. Plastic might substitute equally for bottles as an alternative to cans without being a complete enough substitute for bottles in all bottle uses to be considered in the same market as bottles. 
constrained by competition from bottles, it remains equally limited by competition from plastic. Unfortunately, this point is not readily translated into an operational rule. Just as the degree of "closeness" between cans and bottles eludes precise specification once they are assigned to separate markets, so also does the closeness of plastic containers to cans and bottles. However, it would certainly be inconsistent for one to ignore the imperfect plastic substitutes while making the imperfect substitutability of cans and bottles determinative. Perhaps all one can require is a rule of consistency: If a plaintiff attempting to block a cross-market merger offers evidence concerning the substitutability of cans and bottles, then the defendant also should be allowed to use similar kinds of evidence to show that other products are equally substitutable.

Of course, merely identifying a third product does not necessarily eliminate the problem addressed here. Suppose, for example, that the single can producer merges with the single bottle firm. If there is only one producer of plastic containers and no other substitute products are available, the aggregate number of producers may still be small enough to permit tacit price coordination that elevates the price of all three products. On the other hand, if there are five producers of each of the three products, parallel mergers among the can and bottle firms would still leave ten decisionmakers. In light of the many difficulties of interproduct coordination, this number is probably enough to ensure independent pricing. Indeed, even if bottles and cans were completely substitutable, ten producers would be enough, since that number of competitors within a single market usually is sufficient to protect competition.

Several conclusions may be drawn. First, tacit price coordination is much more difficult to achieve across two interrelated markets than it is in a single market. Second, such coordination is most likely when both markets are collectively dominated by very few firms, each of which has symmetrical interests in both markets. The symmetrical interests relevant here concern profitmaking opportunities, which are not necessarily a function of market shares alone. Proving the existence of such symmetry in particular cases may not be an easy matter. Third, symmetry is not a logically "necessary" condition to produce adverse effects. It may be sufficient if each two-market firm believes it would not suffer substantially by setting prices close to those that would be set by a two-market monopolist. As a practical matter, however, this condition also would be difficult to prove in particular cases. Fourth, if the second or third point is satisfied-or if both points are ignored for reasons 
of administrative convenience-tacit price coordination between two close but separate markets could nevertheless be achieved merely because the number of two-market firms collectively dominating those markets is very small. Fifth, in order to apply the last point, one could include two subordinate rules of thumb. First of all, in judging the effect of a merger on each of two interrelated markets, one may assume that other equivalent-sized firms (or smaller ones) would also want to merge, and that if one such merger were legal, all other similar ones would also be. ${ }^{17}$ This assumption has the virtue of allowing all similarly situated firms to achieve the same economies, if there are any, realized by the initially merging firms. The other rule of thumb is that one may not ignore the existence of additional independent decisionmakers in other markets that are as closely related to either of the merging firms' two markets as the latter are to each other.

It is not easy to convert these conclusions into legal presumptions, but if the symmetry issue may be ignored, the following presumptions may be reasonable, at least as an initial formulation. The suggested magnitudes are consistent with those that we would apply to horizontal mergers, with an adjustment made for the difficulties of intermarket coordination. A merger between two firms in different markets may be presumed unlawful when all of the following conditions obtain:

(1) The two products are "close" substitutes for each other. "Closeness" need not be so clearly demonstrated as long as it is shown to be increasing; if decreasing, the degree of closeness must be clearly demonstrated.

(2) Each market is highly concentrated, as indicated by a fourfirm concentration ratio of ninety percent or more, or a two-firm concentration ratio of seventy percent or more.

(3) Each merging firm is "substantial," in that it accounts for at least fifteen percent of its market and is among the four largest firms in its market.

(4) There is no other market whose product is an equally close substitute. Or, if there is such a market, it is also highly concentrated, and the aggregate number of substantial firms in the three markets in question is eight or less.

17 This proposition is doubtful even for horizontal mergers; it is based largely upon considerations of administrability. 


\section{Effects on Innovation}

Whatever effects they may have on price competition, interindustry mergers, even among dominant firms, probably have no significant adverse effects upon innovation. The basic reasons for this conclusion are the same as those already set forth in the discussion of extended interdependence.

In United States v. Continental Can Co. ${ }^{18}$ the Supreme Court concluded that "it would make little sense" 19 for the can division of a conglomerate firm to engage in innovating activity that, if successful, would take sales from the bottle division, while the latter was engaged in innovating activity that, if successful, would take sales from the former. In fact, the conglomerate is likely to do just that. As long as the conglomerate does not monopolize either market, its gains from successful innovation in one product will almost certainly exceed any losses caused to the other, and successful innovations by rivals in either product will impose sales losses on both of its products.

Continental Can provides the framework for a hypothetical example that illustrates that the incentive to innovate probably survives intermarket mergers. To the extent that bottles do not compete with cans-which is true for most of their uses-cost-reducing or product-improving innovations on bottles have no effect on can sales. To the extent that the two products do compete, innovations on bottles will reduce can sales no matter who introduces them; obviously, Continental will be much better off if it, rather than its rivals, makes these innovations. Suppose, for example, that Continental's innovations secured an additional $\$ 100$ million in bottle sales, $\$ 20$ million of which was at the expense of the can industry. Assume that, as one of several can producers, Continental would lose only one-fourth of all can sales lost, that is, $\$ 5$ million. Thus, its net gain would be $\$ 95$ million.

To be sure, if Continental produced only bottles, it would have gained $\$ 100$ million rather than $\$ 95$ million. Moreover, the difference could be much larger with a different set of assumptions. But even this modest difference illustrates the point that the bottle innovator who also sells cans makes less from its innovation than it would have made had it been involved only in the bottle industry. If its investment in bottle innovation could have been

18378 U.S. 441 (1964).

19 Id. 465 . This comment actually referred to competing promotional efforts. It was made during the course of the Court's rejection of the district court's finding that Continental would probably continue to innovate in both the bottle and can industries. 
equally successful (that is, if it could have yielded a $\$ 100$-million gain) in some other endeavor that carried an offsetting loss of less than $\$ 5$ million, then the fact of its involvement in the can market would have induced it to channel its innovative efforts into some area other than the bottle industry. In short, the merged can-bottle firm would innovate less in bottles than would a firm producing only bottles. Accordingly, the interindustry merger could reduce innovation.

Three factors, however, severely undercut the force of the last argument. First, it may be far more difficult in practice than it is in a hypothetical for a firm to fine-tune its innovative strategy. Indeed, it is probably impossible for a firm correctly to perceive and gauge all the variables necessary to make these calculations. Second, it is by no means certain that the firm has more lucrative innovational opportunities available in fields unrelated to the bottle industry. Third, by foregoing its innovational opportunities in the bottle industry, the merged firm takes the risk that its rivals will make such innovations. If they do, the merged firm will lose not only the $\$ 5$ million in can sales, but also a large volume of bottle sales. That is, the risk of not innovating must also influence the research and development calculus of the two-market firm. This last risk could more than offset any disincentive to innovate, unless one makes the doubtful assumption that parallel mergers of other can and bottle firms would lead all (or most) of them to reduce their innovative efforts with respect to both products.

As long as some can and bottle firms operate in only one market, their efforts to innovate will proceed unabated by the possibility that, if successful, they would cause losses in the sale of other products by other firms. The fact that one merger is permitted does not mean that other, single-product firms would also want to merge. But let us assume that they want to do so, and that permission for one merger implies permission for others as well. Let us also assume that, after these mergers have been completed, we end up with "relatively few" firms, each of which operates in both markets. ${ }^{20}$ Even so, it seems reasonable to suppose that incentives

20 At the conference at which this paper was presented, Professor Joseph Brodley correctly pointed out that if this development reduces price competition and thus leads to reduced output, that result alone might reduce the gains from some innovations and thus could reduce the incentive for innovative activity. For example, the gain from a cost-reducing innovation would decrease as a firm's output decreases. Nevertheless, the cost saving produced by innovation might enable the innovator to increase his market share and to profit substantially, even if the price level exceeds the competitive level and industry output is below that which a competitive industry would produce. 
to innovate will continue. Tacit collusion on innovation is extremely rare, if not entirely absent, even in those situations that encourage price coordination among oligopolists. Such collusion is seldom found within a single market and is equally rare when two markets are involved. To be sure, each two-market firm might conclude that its gains from an innovation in one product would be reduced by the diversion of its own sales of the other product. Nevertheless, the potential for substantial gains at the expense of one's rivals would remain. In conclusion, we do not contend that an interindustry merger could never significantly impair innovation, but that the risk of impairment is modest in view of the incentives for non-price competition existing even within a single oligopolistic market. ${ }^{21}$

\section{Conclusion}

Interindustry mergers may have substantial anticompetitive effects only when several conditions obtain: (1) both markets must be significantly non-competitive; (2) the resulting two-market firms created by the merger must be able to dominate price determination in both markets; and (3) the dominant firms' respective interests in the two markets must be similar. Even when these conditions have been met, however, cooperative solutions still may be impeded by the additional complexities of coordinating prices over two or more partially related markets whose precise interrelationships are diffcult to determine. And, of course, the existence of one or more other partially competing products to which conglomerate ownership does not extend may further limit any adverse effects.

There is considerably less reason to prevent interindustry mergers than there is to attack horizontal mergers that create oligopoly. The effect of interindustry mergers is analogous, and possibly equivalent, to that of those horizontal mergers that somewhat increase concentration in an already highly concentrated market. There is, therefore, some basis for prohibiting interindustry mergers among dominant firms, or for using the possibility of anticompetitive consequences as an additional reason for prohibition when the merging firms are part of a small group of likely entrants into each other's markets.

21 We reach this conclusion wholly apart from (1) the fact that many congTomerates leave research and development decisions to their various product divisions organized as "profit centers"; and (2) the possibility that the conglomerate may well conclude, for the reasons noted in the text, or for other reasons, that it would benefit from intracompany innovating competition. 
However, as was the case with the prerequisites for "extended interdependence," it is difficult to demonstrate when these conditions have been met. This problem could be moderated by the use of presumptions. One could, for example, adopt the presumptions earlier set forth. Yet one might remain skeptical; presumptions will not simplify the matter if rebutting economic evidence is allowed. On the other hand, conclusive presumptions could cover far too much. That result might not be cause for great concern if such mergers never benefited the economy, but they sometimes do. 